\title{
Long-run estimates of interfuel and interfactor elasticities
}

\section{CCEP Working Paper 1602 Jan 2016}

\section{Chunbo Ma}

School of Agricultural and Resource Economics, University of Western Australia

\section{David I. Stern}

Crawford School of Public Policy, The Australian National University

\begin{abstract}
Meta-analyses of interfuel and capital-energy elasticities of substitution show that elasticity estimates are dependent on the type of data - time series, panel, or crosssection - and the estimators used. Econometric theory suggests that the between estimator might generate the best estimates of long-run elasticities but no existing estimates of elasticities of substitution have used it. Alternatively, Chirinko et al. argued in favor of estimating long-run elasticities of substitution using a long-run difference estimator. We provide estimates of China's interfuel and interfactor elasticities of substitution using the between and long-run difference estimators. To address potential omitted variables bias, we add province level inefficiency and national technological change terms to our regression model. The results show that demand for coal and electricity in China is very inelastic, while demand for diesel and gasoline is elastic. With the exception of gasoline and diesel, there are limited substitution possibilities among the fuels. Substitution possibilities are greater between energy and labor than between energy and capital. The results are quite different to some previous studies for China but coincide well with the patterns found in meta-analyses for long-run estimates of elasticities of substitution.
\end{abstract}




\title{
Keywords:
}

Energy; substitution; elasticity; demand; China

\section{JEL Classification:}

D24, Q40

\section{Suggested Citation:}

Ma, C. and Stern, D.I. (2016), Long-run estimates of interfuel and interfactor elasticities, CCEP Working Paper 1602, Jan 2016. Crawford School of Public Policy, The Australian National University.

\author{
Address for Correspondence: \\ David I. Stern \\ Professor \\ Crawford School of Public Policy \\ The Australian National University \\ 132 Lennox Crossing \\ Acton \\ ACT 2601 \\ Australia \\ Tel: +61 261250176 \\ Email: david.stern@anu.edu.au
}

The Crawford School of Public Policy is the Australian National University's public policy school, senving and influencing Australia, Asia and the Pacific through advanced policy research, graduate and executive education, and policy impact.

The Centre for Climate Economics \& Policy is an organized research unit at the Crawford School of Public Policy, The Australian National University. The working paper series is intended to facilitate academic and policy discussion, and the views expressed in working papers are those of the authors. Contact for the Centre: Dr Frank Jotzo, frank.jotzo@anu.edu.au 


\title{
Long-Run Estimates of Interfuel and Interfactor Elasticities
}

Chunbo Ma

School of Agricultural and Resource Economics, University of Western Australia, Crawley, WA 6009, AUSTRALIA. Email: chunbo.ma@uwa.edu.au. Phone: +61-8-6488-2534.

David I. Stern (corresponding author)

Crawford School of Public Policy, The Australian National University, 132 Lennox Crossing, Acton, ACT 2601, AUSTRALIA. E-mail: david.stern@anu.edu.au. Phone: +61-2-6125-0176.

15 January 2016

\begin{abstract}
Meta-analyses of interfuel and capital-energy elasticities of substitution show that elasticity estimates are dependent on the type of data - time series, panel, or cross-section - and the estimators used. Econometric theory suggests that the between estimator might generate the best estimates of long-run elasticities but no existing estimates of elasticities of substitution have used it. Alternatively, Chirinko et al. argued in favor of estimating long-run elasticities of substitution using a long-run difference estimator. We provide estimates of China's interfuel and interfactor elasticities of substitution using the between and long-run difference estimators. To address potential omitted variables bias, we add province level inefficiency and national technological change terms to our regression model. The results show that demand for coal and electricity in China is very inelastic, while demand for diesel and gasoline is elastic. With the exception of gasoline and diesel, there are limited substitution possibilities among the fuels. Substitution possibilities are greater between energy and labor than between energy and capital. The results are quite different to some previous studies for China but coincide well with the patterns found in meta-analyses for long-run estimates of elasticities of substitution.
\end{abstract}

Key Words: Energy; substitution; elasticity; demand; China

JEL Codes: D24, Q40

Acknowledgements: We thank the Australian Research Council for support under Discovery grant DP120101088: "Energy Transitions: Past, Present and Future" and Dan Phaneuf, Ian Sue Wing, and participants at the International Energy Workshop in Abu Dhabi and a joint ANU-Tsinghua University Workshop in Beijing for useful comments. 


\section{Introduction}

In this paper, we use the between estimator and a long-run difference estimator to estimate interfuel and interfactor elasticities of substitution using the translog cost function and a panel of Chinese provincial data. To reduce potential omitted variables bias, we add productivity terms to our regressions, which should eliminate the main source of correlation between the regressors and the error terms. Our results are quite different to some previous estimates for China but coincide well with the patterns found in meta-analyses for long-run estimates of elasticities of substitution.

Meta-analysis of interfuel shadow elasticities of substitution for coal, oil, gas, and electricity (Stern, 2012) shows that the type of data - time series, panel, or cross-section - and the estimator used in primary studies strongly affect their econometric results. Stern (2012) found that interfuel shadow elasticities of substitution from cross-section studies are greater than unity for all combinations of fuels apart from coal and electricity, though only two studies in the database used cross-section data. Elasticities of substitution are generally smaller for OLS, fixed-effects panel estimates, and time series estimates. Koetse et al. (2008) found similar results for capital-energy elasticities of substitution. However, cross-section estimates may be biased as they only utilize a single time series observation (Pesaran and Smith, 1995). Econometric theory (Pesaran and Smith, 1995; Griliches and Mairesse, 1984; Mairesse, 1990; Hauk and Wacziarg, 2009) suggests that the between estimator - a cross-sectional regression on the mean values over time for each individual - will produce consistent estimates of long-run elasticities under ideal assumptions and produce less biased estimates than traditional panel data estimators in the presence of misspecifications. But this estimator has not been used in the context of interfuel and energy-capital substitution. Chirinko et al. (2011) suggested instead that the interval-difference estimator, which uses the differences 
between two time series averages, might provide superior estimates of long-run substitution possibilities. They used this estimator to estimate the elasticity of substitution between capital and labor using a CES production function, but again, estimators of this sort have not been used to estimate interfuel or capital-energy elasticities of substitution.

Estimates of interfuel and energy-capital elasticities of substitution are particularly relevant to the estimation of the costs of climate mitigation. There are widely divergent opinions on the costs of climate mitigation policies and their impact on economic growth ( $\mathrm{Lu}$ and Stern, in press). There has been extensive effort to model the costs of climate change mitigation and adaptation using computable general equilibrium (CGE) models. Such models critically depend on the possibilities for technological change and substitution between energy and other inputs as well as among fuels. The parameters that govern these possibilities - the elasticities of substitution - "are the single most important parameters that affect the[ir] results." (Bhattacharya, 1996, 159). Furthermore, "in the economic literature, there is little consensus about different elasticities for energy products" (Bhattacharya, 1996, 159). The meta-analyses discussed above find a large dispersion in the estimated elasticities of substitution between fuels and between energy and capital and that estimates based on timeseries such as those used in the G-Cubed (McKibbin and Wilcoxen, 1999) or IGEM (Goettle et al., 2007) models tend to underestimate the long-run possibilities of substitution between inputs. As China is the largest emitter of greenhouse gases, better estimates of Chinese elasticities are important for estimates of mitigation possibilities and costs. The most relevant elasticities of substitution in the current study are those between electricity, which could be produced renewably, and the various fossil fuels. 
We use Chinese data that is similar to that previously used by H. Ma et al. $(2008,2009)$ to estimate translog cost functions and cost share equations for energy cost and total cost. ${ }^{1}$ This dataset has a good balance of time- and cross-section dimensions compared to other datasets used in the literature (Stern, 2012), and so is suitable for evaluating different panel data estimators. We have province level data on the quantities of the final use of individual fuels and electricity and energy price series from the provincial capitals, which we use to proxy provincial prices. We also have quantity and price data for capital, labor, and output. The dataset has a cross-section dimension of 30 and a time series dimension of eleven years. We aggregate the various types of coal into a single coal input and estimate the energy cost function and cost share equations for coal, gasoline, diesel, and electricity. We also aggregate all energy types into a single energy input and carry out a similar analysis for capital, labor, and energy. The dataset has a couple of shortcomings. There are no natural gas variables in the data and so we can only provide information on three of the interfuel elasticities of substitution analyzed by Stern (2012). Also, our results are not relevant to substitution inside the electricity sector, which is not included in our study, but is obviously a topic of great interest.

We allow for biased technological change and impose concavity on the cost function. There are very substantial productivity differences between Chinese provinces and these are likely to be correlated with the prices of inputs. To address this potential omitted variables bias, which is more of a concern here than it would be with traditional fixed effects estimation, we add province level inefficiency and technical change terms to our interfactor cost function equation.

\footnotetext{
${ }^{1}$ Our data covers the period 2000-2010 whereas H. Ma et al. (2008) used the period 19952004.
} 
The paper follows the usual layout with the methods section following this introduction, followed by a section describing the data and then the econometric results. The final two sections discuss the results in the context of previous estimates and provide conclusions.

\section{Methods \\ a. Background}

Differences between time-series and cross-section estimates have long been discussed in the econometric literature (Baltagi and Griffin, 1984). In recent decades, this interest has been transferred to panel data, as time-series and cross-sections can be seen as special cases of panels with a cross-section or time dimension of one, respectively.

Apostolakis (1990) and Bacon (1992) surveyed some of the early studies of interfuel substitution elasticities in the OECD countries. Bacon found that panel data studies tended to find more substitutability between fuels as measured by their cross-price elasticities than did time-series studies. He suggested that this was because this data represented long-run elasticities, while time-series data generated short-run elasticities. Apostolakis (1990) came to similar conclusions regarding substitution between aggregate energy and capital. Though short-run elasticities of substitution can be defined and estimated (Mundlak, 1968; Sharma, 2002), the usual definitions of elasticities of substitution are based on long-run responses and, therefore, long-run estimates are desirable. As mentioned in the introduction, recent metaanalyses of interfuel elasticities of substitution (Stern, 2012) and the capital-energy elasticity of substitution (Koetse et al., 2008) find that the largest elasticities of substitution are produced by cross-section estimates and the smallest by time series estimates with fixed effects estimates somewhere in between. Koetse et al. (2008) find a mean Morishima elasticity of substitution in time-series data of 0.22 , in panel data of 0.59 , and in cross-section data of 0.85 . Stern (2012) finds an average shadow elasticity of interfuel substitution of 0.49 
for time series estimates, 1.05 for OLS panel estimates, 1.06 for fixed effects estimates, and 1.60 for cross-section data.

Pesaran and Smith (1995) point out that, if the true data generating process is static, the explanatory variables are uncorrelated with the error term, and any parameter heterogeneity across individuals is random and distributed independently of the regressors, all the usual estimators - time-series, cross-section, and panel OLS, fixed and random effects (FE and $\mathrm{RE}$ ), and between estimates (BE) - should be consistent estimators of the coefficient means. It is the presence of dynamics and/or correlation between the regressors and the error term that results in differences between these estimators. There is no essential difference between time-series and panel estimates, only differences in the likely importance and impact of misspecification. They argue further that, in the absence of correlation between the regressors and the error components, the cross-sectional average of dynamic time-series models for each individual and $\mathrm{BE}$ are consistent. But a traditional cross-section estimate $-\mathrm{BE}$ for a single period - may suffer from a high level of bias. In the presence of coefficient heterogeneity, FE and RE estimators for dynamic models will be inconsistent, as forcing the coefficients to be equal induces serial correlation in the disturbance, which results in inconsistency when there are lagged dependent variables. If the true model is static, static FE and RE should be consistent in the absence of other misspecifications. When the true model is dynamic, the higher the level of correlation between the dependent variable and the lagged variables omitted by a static estimator, the closer static estimates will be to the long-run coefficients (Baltagi and Griffin, 1984). In the non-stationary case, static time-series estimates are superconsistent when the variables are I(1) and cointegrate. But, if the parameters vary across groups, the pooled estimates need not cointegrate. BE also consistently estimates the long-run coefficients when the explanatory variables are non-stationary but strictly exogenous even if there is no cointegration (Pesaran and Smith, 1995). 
However, the assumption that the regressors and errors are uncorrelated does not necessarily hold. The one-way error components model assumes that the error term in a panel model is composed of an individual effect, which varies across individuals but is constant over time, and a remainder disturbance that varies over both time and individuals (Baltagi, 2008). If omitted explanatory variables are correlated with the included regressors, the regressors will be correlated with the individual effects and/or the remainder disturbance (Griliches and Mairesse, 1987). The fixed effects estimator eliminates the individual effects prior to estimation while the between estimator averages over the remainder disturbances of each individual. Therefore, OLS panel, RE, BE, and cross-section estimators will be biased if the regressors are correlated with the individual effects and FE and time-series estimators will be unbiased. But if the correlation is with the remainder disturbance instead, BE will be consistent and all the other estimators will be inconsistent (Griliches and Mairesse, 1987).

Measurement error in the explanatory variables is also problematic in this context as it induces a correlation between the error term and the regressors and biases the estimates towards zero (Hausman, 2001). If measurement errors are non-systematic, BE will average them out over time and will be consistent but biased when the time-series dimension is small, while FE amplifies the noise to signal ratio by subtracting individual means from each timeseries (Mairesse, 1990). Hauk and Wacziarg (2009) conducted a Monte Carlo analysis of an economic growth equation to examine the effects of combined measurement error and omitted variables on alternative panel estimators. The former would be expected to affect FE more and the latter to affect $\mathrm{BE}$ more. They found $\mathrm{BE}$ to have the minimum bias relative to FE, RE, and some GMM estimators commonly used in the growth literature. Other researchers that find superior performance for BE compared to other potential estimators are Pirotte (1999) and Egger and Pfaffermayr (2004). 
We can reduce the potential correlation between the regressors and the individual effects by including additional variables that vary across individuals and are usually omitted from regression analyses. In the case of cost function equations, the most important omitted variable is likely to be the state of technology. Total factor productivity (TFP) varies across Chinese provinces and it is likely that TFP is correlated with input prices. For example, coal is cheaper and TFP lower in the poorer inland provinces. Of course, wage rates will be highly correlated with TFP. Therefore, we may obtain more consistent results by including TFP as an additional variable in the cost function equation for the interfactor estimates. In the current study, we compute these TFP indices both across provinces and over time and include these in the regressions as appropriate.

Chirinko et al. (2011) also propose a method intended to capture long run rather than short run variation - the interval-difference estimator (IDE). They compute the average of each variable over two periods of seven years and then compute the difference between the two periods. The estimator uses the cross-section of these interval-differences. They interpret this estimator "in terms of a low-pass filter placing relatively more weight on low-frequency movements than the traditional approach of first-differencing" (588). They argue that IDE is robust to several potential issues including unit roots, omitted variables bias, misspecified dynamics, and measurement error. In a departure from Chirinko et al. (2011), we compute the differences from the first to the last time series observations in our sample. This allows us to exploit more of the variation in our short sample of 11 years. Differences computed in the two different ways are highly correlated. This estimator then uses the cross-section of differences over time, whereas the between estimator uses the cross-section of averages over time. 
Chirinko et al. (2011) argue that the differenced regressors will likely not be correlated with the productivity shocks but they also provide instrumental variable estimates in case they are. ${ }^{2}$ Instead, we include estimates of the productivity shocks by including the long-run differences of the provincial TFP variables mentioned above.

The relatively regulated energy price regime in China means that the assumption that energy prices at the provincial level are exogenous and driven mostly by differences in transportation costs is not unreasonable. However, following Pindyck (1979), we also use an IV method to take into account the possible endogeneity of price indices for coal and energy in our interfuel and interfactor analyses respectively in both our DE and BE models.

\section{b. Model}

Assuming constant returns to scale, ${ }^{3}$ the translog cost function for a panel of provinces is given by:

$$
\ln C_{i t}=\beta_{0}+\ln U_{i t}+f_{t}+\sum_{j=1}^{J} \beta_{j} \ln P_{j i t}+0.5 \sum_{j=1}^{J} \sum_{k=1}^{J} \beta_{j k} \ln P_{j i t} \ln P_{k i t}+\sum_{j=1}^{J} \gamma_{j} \ln P_{j i t}+\varepsilon_{i t}
$$

where $C$ is unit output cost, $P$ are the prices of the $J$ inputs indexed by $j$ and $k, i$ indexes provinces, and $t$ years. All log prices and the linear time trend, $t$, are normalized at the national sample mean. We also deduct the mean of the log of cost, though this only affects

\footnotetext{
${ }^{2}$ Chirinko et al. (2011) use variables from a prior period as instruments. We find that the mean correlation between the differenced variables for the 2000-2005 period and the 20052010 period is only 0.04 with a standard deviation of 0.34 and a minimum correlation of 0.71 . Therefore, these are likely to be weak instruments and we do not pursue this estimation strategy.

${ }^{3}$ We think it only makes sense to model returns to scale using firm level data. All existing studies on China using a translog specification and macro-level data assume constant returns to scale (Hang and Tu, 2007; Fan et al., 2007; H. Ma et al., 2008; Smyth et al., 2011).
} 
the estimate of $\beta_{0}$, but we do not demean the distance variable. The first parameter on the RHS, $\beta_{0}$, is, therefore, a national mean effect, the second term, $\ln U_{i t}$, is a provincial efficiency effect, which varies over time and is zero in the most efficient province, ${ }^{4}$ and the third term, $f_{t}$, is a national time effect with mean zero. The final term in the equation, $\varepsilon_{i t}$, is a stationary random error term with a mean of zero. The $\beta_{j k}$ coefficients are not that meaningful in themselves, but using our estimation methods, the $\beta_{j}$ 's are the expected cost shares at the sample mean. The $\gamma_{j}$ coefficients are easily interpretable as technical change biases. $\gamma_{j}>0$ implies that technical change is factor $j$ using - the cost share of that input rises over time, ceteris paribus - and $\gamma_{j}<0$ indicates that technical change is factor $j$ saving.

As we assume constant returns to scale, in our interfactor analysis $C$ is total cost per unit of real gross output. ${ }^{5}$ In our interfuel analysis, $C$ is the cost per unit of energy calculated as cost of energy divided by the aggregate energy input index (Pindyck, 1979). We do not include provincial TFP terms in the interfuel cost function. However, we do include the technical change bias terms.

We impose the standard homogeneity and symmetry conditions on the parameters in all our estimates. Homogeneity of degree one in prices is imposed by deducting the log price of the $J$ th input from the prices of the first $J-1$ inputs. For the interfuel analysis we use the price of diesel as the $J$ th price or numeraire and for the interfactor analysis we use the price of labor as the numeraire. The cost function should also be concave in input prices. We test the concavity of the cost function at the reference point. We found that the concavity assumption was violated for the interfuel substitution model but not for the interfactor substitution model.

\footnotetext{
${ }^{4}$ The inefficiency term is the log of the distance of the province from the efficient frontier. A distance of unity places a province on the frontier and hence the log of distance in this province - in our sample Shanghai - is zero. See the next subsection for details of computation of distance and TFP.

${ }^{5}$ See the following subsection for details of the computation of gross output.
} 
Therefore, we imposed concavity on the interfuel model using the method of Ryan and Wales (2000). However, we report the original coefficients of the cost function as in equation (1) rather than the coefficients estimated in the Ryan and Wales method and we compute their standard errors using the delta method.

The standard cost share equation based on Shephard's Lemma (Shephard, 1953) for input $j$ is given by:

$$
S_{j i t}=\beta_{j}+\sum_{k=1}^{J} \beta_{j k} \ln P_{k i t}+\gamma_{j} t+v_{j i t}
$$

where $v_{j i t}$ is a random error term. Only the first $J-1$ equations need to be estimated as the shares sum to unity. Using the Jarque-Bera test we could not reject the hypotheses that both the share data across provinces and the differenced share data are normally distributed. Hence the simple cost share functional form is appropriate. To apply the between estimator to (2) we estimate the cross-sectional regressions:

$$
M\left(S_{j i}\right)=\beta_{j}+\sum_{k=1}^{J} \beta_{j k} M\left(\ln P_{k i}\right)+M\left(v_{j i}\right)
$$

where $M()$ is the between operator that averages data over time in each province $i$. As there are no longer observations for individual time periods, we drop the time subscript. Because the $\log$ prices are normalized at the national sample mean, $\beta_{j}$ is an estimate of the national mean cost share and can be used in elasticity formulae (Stern, 2011). Because of its zero mean, the technical change bias has been averaged away. The simplest approach is to estimate only the $J$-1 equations (3), imposing the cross-equation symmetry restrictions. However, better estimates might be obtained and degrees of freedom increased by jointly 
estimating (3) and the cost function itself (Leon-Ledesma et al., 2010). Averaging (1) over time yields:

$$
\begin{gathered}
M\left(\ln C_{i}\right)=\beta_{0}+M\left(\ln U_{i}\right)+\sum_{j=1}^{J} \beta_{j} M\left(\ln P_{j i}\right)+ \\
0.5 \sum_{j=1}^{J} \sum_{k=1}^{J} \beta_{j k} M\left(\ln P_{j i} \ln P_{k i}\right)+\sum_{j=1}^{J} \gamma_{j} M\left(\operatorname{tn} P_{j i}\right)+M\left(\varepsilon_{i}\right)
\end{gathered}
$$

As the national time effect has a mean of zero it has been averaged away but the technical change bias terms are not eliminated. ${ }^{6}$ Estimating (3) and (4) jointly takes advantage of crossequation restrictions but no cross-equation restrictions can be imposed on the $\gamma_{j}$ coefficients.

Differencing (2) yields:

$$
D\left(S_{j i}\right)=\sum_{k=1}^{J} \beta_{j k} D\left(\ln P_{k i}\right)+\gamma_{j} D(t)+D\left(v_{j i}\right)
$$

where $D()$ is the long-run differencing operator applied to the data for each province $i$. The estimation equation for the cost function is:

$$
D\left(\ln C_{i}\right)=D\left(\ln U_{i}+f\right)+\sum_{j=1}^{J} \beta_{j} D\left(\ln P_{j i}\right)+
$$

\footnotetext{
${ }^{6}$ As the translog function is non-linear in the variables, the mean value of cost may not coincide with the sample mean of the prices. Therefore, it is not appropriate to instead use (1) with the time-averaged means of the variables substituted in places of the time series of the variables. Instead the interaction terms should be computed first and then averaged. Also the biased technical change component of the time effect is not averaged away because, in general, $M(t) M\left(\ln P_{j i}\right)=0$ but $M\left(t \ln P_{j i}\right) \neq 0$.
} 


$$
0.5 \sum_{j=1}^{J} \sum_{k=1}^{J} \beta_{j k} D\left(\ln P_{j i} \ln P_{k i}\right)+\sum_{j=1}^{J} \gamma_{j} D\left(t \ln P_{j i}\right)+D\left(\varepsilon_{i}\right)
$$

Estimating (5) and (6) jointly takes advantage of additional cross-equation restrictions but no cross-equation restrictions can be imposed on the ${ }_{j}$ coefficients. For the interfuel model we do not include distance or national TFP terms but we do include the constant $D(t)$, while in the interfactor model there is no constant in the cost function equation.

In order to compare our proposed estimators to more conventional approaches we also estimate a fixed effects model. The cost function is estimated using:

$$
F\left(\ln C_{i t}\right)=\sum_{j=1}^{J} \beta_{j} F\left(\ln P_{j i t}\right)+0.5 \sum_{j=1}^{J} \sum_{k=1}^{J} \beta_{j k} F\left(\ln P_{j i t} \ln P_{k i t}\right)+\sum_{j=1}^{J} \gamma_{j} F\left(t \ln P_{j i t}\right)+F\left(\varepsilon_{i t}\right)
$$

where $F()$ is the fixed effects operator that first subtracts provincial means from each of the time series and then subtracts national time means from each time period. Therefore, we use both provincial and annual effects. We do not include the productivity variables in the equation. We estimate the cost share equations using the following equations:

$$
F\left(S_{j i t}\right)=\sum_{k=1}^{J} \beta_{j k} F\left(\ln P_{k i t}\right)+F\left(v_{j i t}\right)
$$

As we aggregate various types of coal into a single coal input using the Divisia index in the interfuel model and similarly aggregate the various types of energy into a single index in the interfactor model, the aggregated coal and energy prices are quantity weighted and 
endogenously chosen. We follow Pindyck (1979) and use instrumental variables to estimate the models. We represent the price of aggregated coal (i.e. the average cost of aggregated coal for a producer choosing different coal products) by a homothetic translog cost function with constant returns to scale. Estimation of the share equations implied by this cost function allows us to generate the fitted cost function, which provides an instrumental variable for the price of the aggregated coal input. We also create additional instrumental variables for the interactions between the coal price and other variables by interacting the fitted price of the aggregated coal with the prices of other inputs and time. We follow the same procedure for the interfactor substitution estimation. We estimate the share equations implied by a homothetic translog cost function for the price of the aggregated energy input, and then generate instruments using the fitted energy cost and its associated interactions.

\section{c. Computing Gross Output and Distance and Total Factor Productivity}

Gross output and value added are related as follows:

$$
P_{G} G=P_{Q} Q-P_{E} E
$$

where $Q$ is gross output, $G$ is GDP, $E$ is energy, and the $P_{i}$ are their prices as indicated by the subscripts. ${ }^{7}$ Assuming that the price of GDP and gross output are equal, we can compute gross output as follows:

$$
Q=G+\frac{P_{E}}{P_{G}} E
$$

Based on Hsieh (2002), we compute total factor productivity starting from the assumption that, under constant returns to scale, the value of output must equal the value of input and so

\footnotetext{
${ }^{7}$ Obviously, gross output should really also add back in the value of all other intermediate inputs besides energy, but then we would need to also include these inputs in our cost function. Given data limitations, the only intermediate input we consider is energy.
} 
the ratio of the value of output in two different provinces or years $m$ and $n$ must equal the ratio of the value of their inputs:

$$
\frac{P_{Q m} Q_{m}}{P_{Q n} Q_{n}}=\frac{\sum_{j} P_{j m} X_{j m}}{\sum_{j} P_{j n} X_{j n}}=\bar{P}_{m n} \bar{X}_{m n}
$$

where $\bar{P}_{m n}$ and $\bar{X}_{m n}$ are indices for the ratios of prices and quantities, respectively, of inputs across the two provinces or years. Then rearranging (11) we have:

$$
\frac{Q_{m}}{Q_{n}} / \bar{X}_{m n}=\frac{P_{Q n}}{P_{Q m}} \bar{P}_{m n}
$$

Given that the LHS is the primal index of the TFP ratio for two provinces or years as given by Feenstra et al. (2013), the RHS is the dual index of the TFP ratio for the two provinces or years. Following Feenstra et al. (2013), who use the Divisia index to approximate the quantity index, we approximate the price index using the Divisia index.

For DE we compute a TFP time series for each province using the RHS of (12) and then take the difference in log TFP between the last and first years for each province. For BE we compute the relative TFP of each province to the TFP in the most productive province (Shanghai). This is, therefore, the distance of each province from the efficient frontier. We compute the distance of all provinces in each year; take logs, and then average across years in each province.

\section{d. Elasticities}

We compute own and cross-price elasticities and Morishima and shadow elasticities of substitution. For the normalized translog cost function, the own and cross-price net elasticities at the sample mean are given by: 


$$
\begin{gathered}
\eta_{j j}=\frac{\partial \ln X_{j}}{\partial \ln P_{j}}=\frac{\beta_{j j}+\beta_{j}^{2}-\beta_{j}}{\beta_{j}} \\
\eta_{j k}=\frac{\partial \ln X_{j}}{\partial \ln P_{k}}=\frac{\beta_{j k}+\beta_{j} \beta_{k}}{\beta_{j}}
\end{gathered}
$$

We use the delta method to compute the standard errors of these mean elasticities. Positive cross-price elasticities indicate p-substitutes and negative cross-price elasticities pcomplements. ${ }^{8}$ Morishima and shadow elasticities of substitution assess the difficulty of substitution by measuring the response of the factor quantity ratio to a change in the factor price ratio holding the prices of other inputs and output constant. Values between zero and unity indicate poor substitutability and values above unity high substitutability. ${ }^{9}$ Unless cost is also held constant, the response of the factor quantity ratio depends on which price in the price ratio changes. The Morishima elasticities are asymmetric because they do not hold cost constant while the shadow elasticities are symmetric because they hold cost constant. The symmetric shadow elasticities are good summary statistics of the overall degree of substitutability between inputs.

At the sample mean, the Morishima elasticity of substitution for a change in the price of input $j$ is given by:

\footnotetext{
${ }^{8}$ p-substitutes and complements are the standard definitions of substitutes and complements measuring the response of factor quantities to changes in factor prices. By contrast qsubstitutes and q-complements are defined by the reaction of factor prices to factor quantities. Inputs are usually q-complements - an increase in the level of other inputs increases their marginal product but could be p-complements or p-substitutes. Simply referring to inputs as complements or substitutes is, therefore, confusing (Stern, 2011).

${ }^{9}$ The former are often referred to as complements and the latter substitutes but this terminology is again confusing. When there are only two inputs they must be net psubstitutes irrespective of the value of the elasticity of substitution.
} 


$$
\mu_{j k}=\frac{\partial \ln X_{k}}{\partial \ln P_{j}}-\frac{\partial \ln X_{j}}{\partial \ln P_{j}}=\frac{\beta_{j k}+\beta_{j} \beta_{k}}{\beta_{k}}-\frac{\beta_{j j}+\beta_{j}^{2}-\beta_{j}}{\beta_{j}}
$$

The shadow elasticity of substitution at the sample mean can be expressed as the share weighted mean of the Morishima elasticities (Chambers, $1988^{10}$ ):

$$
\begin{gathered}
\sigma_{j k}=\frac{S_{j}}{S_{j}+S_{k}} \mu_{k j}+\frac{S_{k}}{S_{j}+S_{k}} \mu_{j k} \\
=\frac{\beta_{j}}{\beta_{j}+\beta_{k}}\left(\frac{\beta_{j k}+\beta_{j} \beta_{k}}{\beta_{j}}-\frac{\beta_{k k}+\beta_{k}^{2}-\beta_{k}}{\beta_{k}}\right)+\frac{\beta_{k}}{\beta_{j}+\beta_{k}}\left(\frac{\beta_{j k}+\beta_{j} \beta_{k}}{\beta_{k}}-\frac{\beta_{j j}+\beta_{j}^{2}-\beta_{j}}{\beta_{j}}\right) \\
=\frac{1}{\beta_{j}+\beta_{k}}\left(2\left(\beta_{j k}+\beta_{j} \beta_{k}\right)-\beta_{j} \frac{\beta_{k k}+\beta_{k}^{2}-\beta_{k}}{\beta_{k}}-\beta_{k} \frac{\beta_{j j}+\beta_{j}^{2}-\beta_{j}}{\beta_{j}}\right)
\end{gathered}
$$

Allen-Uzawa elasticities of substitution are frequently reported in studies of substitution possibilities but we do not report them. ${ }^{11}$ When there are only two inputs and constant returns to scale, the elasticity of substitution is unambiguously defined - the Morishima and Shadow elasticity formulae reduce to the Allen-Uzawa elasticity of substitution. But when there are more than two inputs this is not the case - the Allen-Uzawa elasticities have the same sign as the cross-price elasticities and no longer measure the difficulty of substitution on a zero to infinity scale.

Following Pindyck (1979), the total own and cross-price elasticities for fuel $j$ with respect to the price of fuel $k$ are given by:

\footnotetext{
${ }^{10}$ Note, that this formula differs from that in Chambers (1988) because Chambers' notation for the Morishima elasticity of substitution is non-standard.

${ }^{11}$ The Allen-Uzawa elasticities of substitution are equal to the cross-price elasticities of substitution divided by the relevant cost share: $\alpha_{j k}=\eta_{j k} / S_{k}$.
} 


$$
\eta_{j k}^{T}=\eta_{j k}+\eta_{E E} \hat{S}_{k}
$$

where $\eta_{E E}$ is the own price elasticity of aggregate energy and $\hat{S}_{k}$ is the fitted cost share for fuel $k$. To compute the elasticity at the reference point we again substitute the estimate of $\beta_{k}$ for $\hat{S}_{k}$ and we assume that the energy own price elasticity is a fixed known parameter.

\section{Data}

Our dataset consists of provincial level data for China for real GDP, the quantities of the final use of seven individual fuels and electricity, capital, and labor, price series for capital and labor, and energy price series from the provincial capitals, which we use to proxy provincial energy prices. The data cover all provinces, province level municipalities, and autonomous regions of the People's Republic of China except Tibet for the years 2000 to 2010. Therefore, the panel has a cross-section dimension of 30 provinces and a time series dimension of eleven years. Table 1 provides summary statistics for these raw variables. This shows the extraordinary growth rates of many variables in China over this period. The exceptionally high growth rate for coal briquettes reflects growth from a very small base in 2000 when several provinces did not report any use of this fuel. The growth rate for China as a whole was $32 \%$ per annum over the 11 years.

We obtain the individual fuel consumption data from the China Energy Yearbooks (CEY). The $C E Y$ provides detailed data on final consumption of different fuel types by sector, province and year. Energy used as intermediate inputs, such as coal used to generate electricity and heat and to produce coke, is excluded. We include eight fuel types: steam coal, coking coal, coke, briquettes, coal gas, gasoline, diesel and electricity. We aggregate final consumption of each fuel type from the five sectors: "Farming, Forestry, Animal Husbandry, Fishery and Water Conservancy", "Industry", "Construction”, "Transport, Storage and Post" 
and "Wholesale, Retail Trade, Hotel and Catering". Rural and urban residential consumption and fuel use for non-energy purposes are excluded.

We collect fuel price data from two sources. China's National Development and Reform Commission (NDRC) collects perhaps the most authoritative commodity price data from 36 large cities including all provincial capitals. We use fuel prices collected in the provincial capital cities as an indicator of provincial prices. As price collection is conducted by the NDRC three times a month, we construct an annual price series by taking the average of these price data for each province. China Price Statistical Yearbooks (CPSYs) provide the second source of data. The CPSYs reported provincial prices on twelve fuels including seven used in this study. Both the NDRC data and the CPSY data have missing values. Most missing values in the NDRC data appeared in early years while the CPSY ceased to report fuel prices after 2006. Where the value is missing in the NDRC data but available in the $C P S Y$ data, we use the value reported in the $C P S Y$ data to replace the missing value in the NDRC data. Remaining missing values in the NDRC data are then linearly interpolated. Total employment data, which include all employed persons in urban and rural sectors, are obtained from the China Statistical Yearbooks (CSY). The CSY also provides an income approach decomposition of GDP as the sum of compensation of employees, net taxes of production, depreciation of fixed assets, and operating surplus. Compensation of employees includes the total payment of various forms to employees for the productive activities they are engaged in. It includes wages, bonuses and allowances, which the employees earn in cash or in kind. It also includes the free medical services provided to the employees and medicine expenses, transport subsidies and social insurance, and housing funding paid by the employers. Compared to wages, which were used in H. Ma et al. (2008), this is clearly a 
superior indicator for actual compensation of labor. Using total employment and total compensation, we can construct the price index for labor.

The sum of the other three components of the decomposed GDP - net taxes of production, depreciation of fixed assets, and operating surplus - effectively gives the compensation of capital. Unfortunately, the $C S Y$ does not provide capital stock statistics. The capital stock series are provided by $\mathrm{Wu}(2009)$ with updated statistics obtained from the author. Using total compensation of capital and the capital stock series, we constructed the price index for capital. Our measure of total compensation of capital is also superior to that used by H. Ma et al. (2008), who simply used the product of the capital stock and the price index of fixed assets reported in the $C S Y$.

In the interfactor substitution analysis we use three factor inputs: aggregate energy use, capital services, and labor use, aggregating the eight energy carriers into a single energy input. For the interfuel substitution analysis we use four energy inputs: aggregated coal, gasoline, diesel, and electricity aggregating the five types of coal in our data into a single coal input. $^{12}$

As the between estimator depends on variation in relative prices across the provinces, we cannot set the base year price or quantity index in each province to an arbitrary level as is often done in cost function analyses. Also, if we simply compute the average cost of energy per joule in each province then the price will depend on the mix of fuels. High quality fuels such as electricity have much higher prices than low quality fuels such as coal. Therefore, we

\footnotetext{
${ }^{12}$ Ideally, we would include natural gas; however, we excluded natural gas from the analysis for two reasons. First, as rural and urban residential consumption and fuel use for non-energy purposes are excluded, several provinces have zero reported industrial consumption of natural gas. Second, the price data we collected has a substantial number of missing values for natural gas prices. Because of these issues, none of the existing studies on China use data on natural gas.
} 
need to use index number methods to compute proper price indices for coal and energy for each province in each year.

We first computed Laspeyres price indices for each province in each year, using the national average price of coal or energy in RMB per joule as the base price. The Laspeyres index evaluates the price level in each province using the national average quantities as weights. This gives a relative energy or coal price index for each province in each year but these prices cannot be compared across years. We address this by multiplying these relative price indices by a national price index time series to obtain a time series in each province in each year. We use the Divisia index to compute the national level price index.

Figures 1 to 3 show the variation in some of our constructed variables across China. In 2010 the coal price index varies by roughly a factor of two across provinces (Figure 1). In general, prices are higher in the coastal provinces and cheapest in the mid-western and northwestern provinces such as Chongqing, Shaanxi, Ningxia, Inner Mongolia, and Xinjiang.

Distance from the technological frontier varies by a factor of roughly three (Figure 2). Shanghai is the most productive province and Guangdong and Tianjin and other coastal provinces are relatively close to the frontier. Furthest from the frontier are the western provinces of Qinghai, Ningxia, and Guizhou. Figure 3 shows that there has been some convergence in TFP over time. The slowest TFP growth was in Beijing and the highest in Sichuan and Hainan.

\section{Econometric Results}

Following Pindyck (1979), we use iterative seemingly unrelated regressions to estimate the fitted prices of the aggregated coal input for use as instruments in the interfuel substitution model and the fitted prices of the aggregated energy input for the interfactor substitution 
model. ${ }^{13}$ Then we estimate the BE model (3) and (4) simultaneously using iterative 3 -stage least squares regression imposing symmetry and homogeneity restrictions for both the interfuel and interfactor cost function systems. ${ }^{14}$ We estimate the DE model (5) and (6) in the same way. The diesel and labor prices are treated as the numeraire in the interfuel and interfactor estimations, respectively, and we drop the corresponding cost share equations. We retrieve the parameters for these variables using the homogeneity restrictions and compute their standard errors using the delta method. We also test the concavity of the cost function at every data point and impose concavity using the method of Ryan and Wales (2000) if concavity is violated.

\subsection{Interfuel Substitution}

We first estimated the unconstrained interfuel substitution model using BE and found that the estimated energy cost function violates the concavity condition at all sample observations. The energy cost function estimated using unconstrained DE is only concave at 58 out of the total 330 sample observations. Therefore, we impose concavity. Table 2 presents the results from the constrained BE and DE estimation. Table 3 provides the implied own and cross price elasticities and Table 4 the Morishima and shadow elasticities of substitution.

The parameters estimated using BE and DE are remarkably similar - the main differences are in the technical change biases, which are not subject to cross-equation restrictions in the $\mathrm{BE}$ estimates (Table 2). The FE estimates differ more substantially. All three methods find coalusing technical change $\left(\gamma_{C}>0\right)$, but DE and FE find gasoline-saving $\left(\gamma_{G}<0\right)$ and $\mathrm{BE}$ and

\footnotetext{
${ }^{13}$ To save space, these first-stage results are not reported but are available upon request.

${ }^{14}$ We use the procedure NLSYSTEM in RATS. This estimates the model using the generalized method of moments and an optimal weighting matrix (Estima, 2010). Hence there is no need to request the program to compute robust standard errors.
} 
FE electricity-saving technical change $\left(\gamma_{X}<0\right)$, with the other biases statistically insignificant.

It is particularly remarkable that the estimated $\beta_{j}$ 's are very similar for the three estimators when DE and FE do not explicitly utilize cross-equation restrictions to estimate them. However, the concavity restrictions involve these parameters. A surprising result is that the average rate of cost reduction, ceteris paribus, given by the DE estimates is $1 \%$ per annum. We had assumed that it is hard to make technological progress in composing an energy aggregate from different fuels.

The BE and DE estimates of own- and cross-price elasticities are similar, but the DE estimates are consistently greater in absolute value and more of them are statistically significant (Table 3). For DE, all the own-price elasticities are negative and statistically significant - gasoline demand is elastic and the demand for the other fuels inelastic especially that of coal. Among the significant cross-price elasticities, coal and electricity and diesel and electricity are complements and gasoline and diesel substitutes, as we would expect. By contrast, the fixed effects estimates of elasticities are all very small, though several are significantly different to zero.

Moving on to the elasticities of substitution (Table 4), we make the following observations:

- As expected given the parameter estimates, the elasticities estimated by BE and DE are similar but the BE elasticities are mostly smaller in absolute value and none of them is statistically significant. The FE elasticities are all very small and insignificantly different to zero.

- For BE, the shadow elasticities of substitution are less than unity (indicating poor substitutability) except for between gasoline and diesel, which are good substitutes. The 
Morishima elasticities show that gasoline is a good substitute for coal and electricity if the gasoline price changes, but not otherwise. Three of the DE shadow elasticities are greater than unity and four are significantly different to zero.

- The elasticity of substitution between coal and electricity is very close to zero.

\subsection{Interfactor Substitution}

Again, we first estimated the cost function systems without imposing the concavity constraints. Using BE, the estimated cost function satisfies the concavity condition for most sample observations and is concave at the reference point. Using DE, the estimated cost function is concave for all sample observations. Using FE the estimated cost function is also concave at the reference point. Therefore, we did not impose concavity on the interfactor substitution models. Table 5 presents the estimated parameters and Table 6 provides the implied own and cross price elasticities and Morishima and shadow elasticities of substitution.

The parameter estimates vary more across estimators than the interfuel parameter estimates do (Table 5). ${ }^{15} \mathrm{BE}$ finds no statistically significant technical change biases but some indication of energy-using and labor-saving biases $\left(\gamma_{E}>0, \gamma_{L}<0\right)$, which are both statistically significant for FE, while DE finds capital-using and labor-saving technical change $\left(\gamma_{K}>0, \gamma_{L}<0\right)$. Because of the much larger number of degrees of freedom most of the FE parameter estimates are highly statistically significant.

The BE and DE estimates of the own- and cross-price elasticities (Table 6) are fairly different with no apparent pattern to the differences. All the own price elasticities are inelastic. The BE

\footnotetext{
${ }^{15}$ Wondering whether this is because there are no cross-equation restrictions on the $\beta_{j}$ 's and no concavity restrictions to impose them implicitly, we restricted the $\beta_{j}$ 's to be equal to the mean cost shares. This did not change the other parameters by very much.
} 
estimates find that energy and capital are both substitutes for labor. The DE estimates find that energy and capital are also substitutes. The FE estimates are mostly smaller or much smaller in absolute value.

Moving onto the elasticities of substitution (Table 6), we have four key observations:

- All Morishima and shadow elasticities of substitution between factors are significant and less than unity for the DE estimator.

- BE finds that capital and energy are poor substitutes with an elasticity of substitution that is insignificantly different from zero and finds that energy and labor and capital and labor are good substitutes, though only when it is the price of labor which changes.

- For both estimators, substitution elasticities are higher between energy and labor than between energy and capital.

- All the FE estimates of elasticities of substitution are smaller than their BE and DE counterparts.

\section{Comparison with Existing Literature}

\subsection{Interfuel Substitution}

The elasticities estimated in this study are mostly smaller than the elasticities for the United States estimated using meta-analysis (Stern, 2012). The latter are all greater than unity with the exception of the coal-electricity elasticity (0.176). However, Stern (2012) concluded that there is no simple relationship between the values of the interfuel elasticities of substitution and the level of economic development, size of economies etc. and so it is unknown why there is this difference between the two economies. 
But how do our estimates compare to previous estimates for China? Stern (2012)'s metaanalysis included four studies: Fisher-Vanden et al. (2004), Hang and Tu (2007), H. Ma et al. (2008), and H. Ma et al. (2009). Two more recent studies are Serletis et al. (2011) - who investigate interfuel substitution for a number of countries including China - and Smyth et al. (2012) - who examine interfuel substitution in the Chinese iron and steel sector. We summarize the results of these studies in Table 7 as shadow elasticities. We use the long-run Morishima elasticities from Serletis et al. (2011) and weight them using the average cost shares from the current study. The averages of the seven regions in H. Ma et al. (2009) are very close to the national estimates and so we do not report results from that study. We use the most recent estimates of Hang and Tu (2007) and Smyth et al. (2012).

Data types and methods of estimation differ across the studies. Ours is the only study to jointly estimate a cost function and first order conditions, which is likely to produce superior estimates (Leon-Ledesma et al., 2010). Fisher-Vanden et al. (2004) is a firm-level crosssectional analysis. Hang and $\mathrm{Tu}$ (2007) use a national level time series and unconstrained logarithmic demand curves. H. Ma et al. (2008) also use a panel data set of seven Chinese regions and fixed effects estimation using the translog cost function. Smyth et al. (2012) estimate a translog production function using ridge regression for a time series from the iron and steel industry. Finally, Serletis et al. (2011) use a normalized quadratic cost function system with concavity imposed and fixed effects for a panel of data for China, India, South Africa, and Thailand.

The most directly comparable study to ours should be that of H. Ma et al. $(2008,2009)$ who use an earlier version of the same dataset as us. However, the shadow elasticities from that study are inversely related to those from our study - for BE the correlation is -0.48 and for DE -0.39. In particular, their highest elasticity is for coal-electricity substitution, which is our 
lowest elasticity and their lowest elasticity is for gasoline-diesel substitution, which is our highest. Our results seem more plausible, as one would expect that it is easier to substitute between gasoline and diesel than between coal and electricity. The coal-electricity elasticity is the smallest in Stern's (2012) meta-analysis. Apart from the difference in estimators fixed effects vs. specifically long-run estimators - we impose concavity, which is one reason why even our fixed effects estimates are very different - and our data covers the period 20002010 whereas they used the period 1995-2004. We also include eight different fuel inputs while they only included four and there are other improvements in our data as mentioned above. Smyth et al.'s (2012) results are likely driven by using ridge regression with a single production function equation. Our results are more similar to those of Serletis et al. (2011) Fisher-Vanden et al. (2004), and Hang and Tu (2007). All these studies find a larger value for the oil-coal elasticity than for the coal-electricity elasticity.

We also compare our results to a few single equation estimates of demand elasticities that use panels of Chinese provincial data. Burke and Liao (2015) find that the coal own-price elasticity in China has increased over time. Using a panel of provincial data from 1998 to 2012 they obtain a "two-year elasticity" of -0.14 for a model that does not allow the elasticity to evolve over time. This is very close to our estimates. Allowing evolution over time, they estimate an elasticity of -0.3 for 2005 (personal communication). Cao and Xie (2011) estimate that the long-run elasticity of demand for diesel is -0.86 between 1999 and 2007. This is very close to our DE estimate of -0.89 .

\subsection{Interfactor Substitution}

Koetse et al. (2008) conducted a meta-analysis of 34 studies of capital-energy substitution. Most studies included in the meta-analysis used data from before 1990 and there were no studies that included China. Koetse et al. (2008) found that short-run (time series) elasticities 
of substitution are around 0.4 for North America and 0.15 for Europe. Long-run (crosssection) elasticities are slightly greater than unity in North America and around 0.8 for Europe. Our BE elasticity is obviously much smaller than these long-run elasticities (and insignificantly different from zero), while our DE estimate is close to estimates for Europe and to Stern and Kander's (2012) estimate for Sweden. The consensus is that the capital-labor elasticity is less than unity for the United States (Acemoglu, 2003; Klump et al., 2007). Here our DE estimate is again closest to expectations for developed countries.

Table 8 reports the available estimates for China. We use the cost shares from our study to weight the Morishima elasticities from other studies. We use Fan et al.'s (2007) estimate for 1993-2003 and Smyth et al.'s (2011) estimates for 2007. Again a variety of methods and data were used to produce these results. Ma et al. (2008) estimate a translog cost function and share equations for a panel of seven Chinese regions, Fan et al. (2007) used only the cost share equations and a time series of national data, Mallick estimates a two input CES production function for a national time series, and Smyth et al. (2011) estimate a translog production function using ridge regression for a time series from the iron and steel industry. Again, ours is the only study to jointly estimate a cost function with the first order conditions.

Our results are very different to Fan et al. (2007) and Smyth et al. (2011) who use less sophisticated methods. Our DE capital-labor elasticity of substitution is almost identical to Mallick's (2012). Results for DE have a similar pattern to those of H. Ma et al. (2008) but are a little larger in each case. There are a number of differences between our study and H. Ma et al.'s. We use a broader coverage of fuel inputs and a dataset covering a different period. More importantly, using wages will underestimate the actual compensation for labor and their studies also seemed to have used incorrect measures of capital services, which will undoubtedly overestimate the actual compensation for capital. 


\section{Conclusions}

In this paper, we use between and interval-difference estimators to provide estimates of interfuel (coal, gasoline, diesel, and electricity) and interfactor (capital, labor, and energy) elasticities of substitution for China. The results show that demand for coal and electricity in China is very inelastic (own price elasticities less than -0.4), while demand for gasoline is elastic $(-1.1$ to -1.7$)$, and for diesel moderately inelastic $(-0.7$ to -0.9$)$. There are very limited substitution possibilities between coal and electricity (shadow elasticity less than 0.1 ) and high substitution possibilities between gasoline and diesel (greater than 1.7). Substitution possibilities are greater between energy and labor (between 0.6 and 1.0) than between energy and capital (between 0.2 and 0.8 ). The results are quite different to some previous studies for China but coincide well with the patterns in meta-analyses for long-run estimates of elasticities of substitution. Interfuel and capital-energy elasticities of substitution are generally lower than estimates for the United States derived from meta-analyses (Koetse et al., 2007; Stern, 2012). These results should be taken into account in CGE models used for assessing climate policy options in China. The marginal cost of abatement for a given reduction in emissions will be higher than would be predicted assuming that Chinese elasticities are the same as US elasticities as some models assume (Lu and Stern, in press).

Our findings potentially have significant policy implications at a time when the Chinese government is under mounting domestic and international pressure to reduce greenhouse gases emissions from burning fossil fuels and particularly coal. Some previous studies (e.g. H. Ma et al., 2008) are generally optimistic about the degree of difficulty in substituting cleaner energy for dirty coal. Our very low estimate of the elasticity of substitution between coal and electricity in final energy consumption suggests that replacing coal with renewably generated electricity in end-use applications will be costly. The electricity market in China is 
still heavily regulated. China launched market reform in the electricity sector in 2003; however only generation was unbundled from transmission and distribution, a competitive wholesale market is not yet established. Because our analysis does not specifically model the energy transformation sectors, no inferences can be drawn from our study with regard to substitution between coal and cleaner sources including natural gas, wind, and solar in the generation of electricity. Some may be optimistic about this substitution given the measures taken by the Chinese government in recent years to promote the penetration of cleaner energy sources and renewable energy in particular. However, this substitution potential may be limited by the fact that China still accounts for half of the annual global coal consumption and half of that is consumed in the electricity sector. The government has implemented a number of retrofitting mandates to close down small and old generation units and replace them with new and large coal-fired units. This massive fleet of newly installed coal-fired units will lock the Chinese economy into a coal-dominated energy supply for the next two to three decades.

The BE and DE results are much more similar for the interfuel substitution system where concavity was imposed, than for the interfactor substitution system where we did not need to impose concavity. It is unclear which of the two estimators should be preferred when they do diverge. As DE imposes cross-equation restrictions on the technical change biases it probably produces more consistent estimates of these. The DE parameters seem to be estimated more precisely than the BE estimates. Further research is needed on the performance of the estimators under alternative restrictions and conditions. On the other hand, our FE estimates of the interfuel cost share system had very poor curvature properties and when we imposed concavity all the interfuel elasticities of substitution effectively became zero. FE estimates of the interfactor system had adequate curvature properties but all the elasticities of substitution are smaller than their BE and DE counterparts. 
Our estimates of interfuel elasticities of substitution are close to those estimated by FisherVanden et al. (2004), who used a large cross-section of micro-data that should also capture long-run substitution possibilities. All this suggests that DE and BE do in fact capture longrun substitution possibilities and FE short-run substitution possibilities, as we predicted. Users of elasticities should make sure that the estimates they use were estimated with an appropriate method that captures the long- or short-run substitution possibilities that they desire.

\section{References}

Acemoglu, D., 2003. Labor- and capital-augmenting technical change. Journal of the European Economic Association 1(1), 1-37.

Apostolakis, B. E., 1990. Interfuel and energy-capital complementarity in manufacturingindustries. Applied Energy 35(2), 83-107.

Bacon, R., 1992. Measuring the possibilities of interfuel substitution. Policy Research Working Paper Series 1031. The World Bank, Washington, DC.

Baltagi, B. H., 2008. Econometric Analysis of Panel Data $4^{\text {th }}$ edition. John Wiley \& Sons, Chichester.

Baltagi, N. H., Griffin, J. M., 1984. Short and long run effects in pooled models. International Economic Review 25(3), 631-645.

Bhattacharya, S. C., 1996. Applied general equilibrium models for energy studies. Energy Economics 18, 145-164.

Burke, P. J., Liao H., 2015. Is the price elasticity of demand for coal in China increasing? China Economic Review 36, 309-322.

Cao J., Xie Y., 2011. Diesel demand per capita elasticities in China, 1999-2007. Qinghua Daxue Xuebao/Journal of Tsinghua University 51(2), 241-244. 
Chambers, R., 1988. Applied Production Analysis: A Dual Approach. Cambridge University Press, Cambridge.

Chirinko, R. S., Fazzari, S. M., Meyer, A. P., 2011. A new approach to estimating production function parameters: the elusive capital-labor substitution elasticity. Journal of Business \& Economic Statistics 29(4), 587-594.

Egger, P., Pfaffermayr, M., 2004. Estimating long and short run effects in static panel models. Econometric Reviews 23(3), 199-214.

Estima, 2010. RATS Version 8: User's Guide. Estima, Evanston, IL.

Fan Y., Liao H., Wei Y. M., 2007. Can market oriented economic reforms contribute to energy efficiency improvement? Evidence from China. Energy Policy 35, 2287-2295.

Feenstra, R. C., Inklaar, R., Timmer, M. P., 2013. The next generation of the Penn World Table. NBER Working Papers 19255.

Fisher-Vanden, K., Jefferson, G. H., Liu H., Tao Q., 2004. What is driving China's decline in energy intensity? Resource and Energy Economics 26, 77-97.

Goettle, R. J., Ho M. S., Jorgenson, D. W., Slesnick, D. T., Wilcoxen, P. J., 2007. IGEM, an Inter-temporal General Equilibrium Model of the U.S. Economy with Emphasis on Growth, Energy and the Environment. Prepared for the U.S. Environmental Protection Agency (EPA), Office of Atmospheric Programs, Climate Change Division.

Griliches, Z., Mairesse, J., 1987. Productivity and R\&D at the firm level, in: Griliches, Z. (Ed.) $R \& D$, Patents, and Productivity. University of Chicago Press.

Hang L., Tu M., 2007. The impacts of energy prices on energy intensity: evidence from China. Energy Policy 35(5), 2978-2988.

Hausman, J. A., 2001. Mismeasured variables in econometric analysis: problems from the right and problems from the left. Journal of Economic Perspectives 15(4), 57-67.

Hauk, W. R., Wacziarg, R., 2009. A Monte Carlo study of growth regressions. Journal of 
Economic Growth 14, 103-147.

Hsieh C. T., 2002. What explains the industrial revolution in East Asia? Evidence from the factor markets. American Economic Review 92(3), 502-526.

Klump, R., McAdam, P., Willman, A., 2007. Factor substitution and factor-augmenting technical progress in the United States: a normalized supply-side system approach. Review of Economics and Statistics 89(1), 183-192.

Koetse, M. J., de Groot, H. L. F., Florax, R. J. G. M., 2008. Capital-energy substitution and shifts in factor demand: A meta-analysis. Energy Economics 30, 2236-2251.

Leon-Ledesma, M. A., McAdam, P., Willman, A., 2010. Identifying the elasticity of substitution with biased technical change. American Economic Review 100, 1330-1357.

Lu Y., Stern, D. I., in press. Substitutability and the cost of climate mitigation policy. Environmental and Resource Economics.

Ma C., Stern, D. I., 2008. China's changing energy intensity trend: a decomposition analysis. Energy Economics 30(3), 1037-1053.

Ma H., Oxley, L. Gibson, J., 2009. Substitution possibilities and determinants of energy intensity for China. Energy Policy 37, 1793-1804.

Ma H., Oxley, L. Gibson, J., Kim, B., 2008. China's energy economy: Technical change. factor demand and interfactor/interfuel substitution, Energy Economics 30, 2167-2183.

Mairesse, J., 1990. Time-series and cross-sectional estimates on panel data: Why are they different and why should they be equal? In: Hartog, J., Ridder, G., Theeuwes, J. (Eds.) Panel Data and Labor Market Studies. Contributions to Economic Analysis No. 192, North-Holland, Amsterdam.

Mallick D., 2012. The role of the elasticity of substitution in economic growth: A crosscountry investigation. Labour Economics 19, 682-694.

McKibbin, W. J. Wilcoxen, P. J., 1999. The theoretical and empirical structure of the G- 
Cubed model. Economic Modelling 16, 123-148.

Mundlak, Y., 1968. Elasticities of substitution and the theory of derived demand. Review of Economic Studies 35, 225-236.

Pesaran, M. H.. Smith, R., 1995. Estimating long-run relationships from dynamic heterogeneous panels. Journal of Econometrics 68(1), 79-113.

Pindyck, R. S., 1979. Interfuel Substitution and the industrial demand for energy: an international comparison. Review of Economics and Statistics 61(2), 169-179.

Pirotte, A., 1999. Convergence of the static estimation toward the long run effects of dynamic panel data models. Economics Letters 63(2), 151-158.

Ryan, D. L., Wales, T. J., 2000. Imposing local concavity in the translog and generalized Leontief cost functions. Economics Letters 67, 253-260.

Serletis, A., Timilsina, G., Vasetsky, O., 2010. Interfuel substitution in the United States. Energy Economics 32, 737-745.

Serletis, A., Timilsina, G., Vasetsky, O., 2011. International evidence on aggregate short-run and long-run interfuel substitution. Energy Economics 33, 209-216.

Sharma, S. C., 2002. The Morishima elasticity of substitution for the variable profit function and the demand for imports in the United States. International Economic Review 43(1), 115-135.

Shephard, R., 1953. Theory of Cost and Production Functions, Princeton University Press.

Smyth, R., Narayan, P. K., Shi H., 2012. Inter-fuel substitution in the Chinese iron and steel sector. International Journal of Production Economics 139, 525-532.

Smyth, R., Narayan, P. K., Shi H., 2011. Substitution between energy and classical factor inputs in the Chinese steel sector. Applied Energy, 88(1), 361-367.

Stern, D. I., 2011. Elasticities of substitution and complementarity. Journal of Productivity Analysis 36(1), 79-89. 
Stern, D. I., 2012. Interfuel substitution: A meta-analysis. Journal of Economic Surveys 26(2), 307-331.

Stern, D. I., Kander, A., 2012. The role of energy in the industrial revolution and modern economic growth. Energy Journal 33(3), 125-152.

Wu Y. R., 2009. China's capital stock series by region and sector. Discussion Paper 09.02, Business School, University of Western Australia. 
Table 1. Summary Statistics 2000-2010

\begin{tabular}{|c|c|c|c|c|c|}
\hline \multirow{2}{*}{ Variables } & \multirow{2}{*}{ Unit } & \multicolumn{2}{|c|}{ Provincial Mean } & \multicolumn{2}{|c|}{ Annual Provincial Growth Rate } \\
\hline & & Mean $^{\dagger}$ & S.D. ${ }^{\dagger}$ & Mean & S.D. \\
\hline Steam Coal Price & yuan/tonne & 333 & 111 & $9 \%$ & $3 \%$ \\
\hline Coking Coal Price & yuan/tonne & 547 & 130 & $13 \%$ & $3 \%$ \\
\hline Briquette Price & yuan $/ 100 \mathrm{~kg}$ & 32.9 & 9.62 & $8 \%$ & $4 \%$ \\
\hline Coke Price & yuan/tonne & 937 & 182 & $13 \%$ & $2 \%$ \\
\hline Coal Gas Price & yuan $/ m^{3}$ & 1.27 & 0.29 & $2 \%$ & $3 \%$ \\
\hline Gasoline Price & yuan/tonne & 5518 & 182 & $10 \%$ & $1 \%$ \\
\hline Diesel Price & yuan/tonne & 4730 & 89.8 & $9 \%$ & $1 \%$ \\
\hline Electricity Price & yuan/kwh & 0.60 & 0.09 & $6 \%$ & $4 \%$ \\
\hline Steam Coal Quantity & mil. tonnes & 23.8 & 16.0 & $6 \%$ & $4 \%$ \\
\hline Coking Coal Quantity & 1000 tonnes & 952 & 1108 & $18 \%$ & $23 \%$ \\
\hline Briquette Quantity & 1000 tonnes & 226 & 309 & $42 \%$ & $23 \%$ \\
\hline Coke Quantity & mil. tonnes & 6.9 & 8.0 & $13 \%$ & $12 \%$ \\
\hline Coal Gas Quantity & bil. $m^{3}$ & 5.41 & 6.78 & $1 \%$ & $23 \%$ \\
\hline Gasoline Quantity & mil. tonnes & 1.73 & 1.19 & $7 \%$ & $5 \%$ \\
\hline Diesel Quantity & mil. tonnes & 3.31 & 2.33 & $14 \%$ & $6 \%$ \\
\hline Electricity Quantity & bil. kwh & 72.5 & 52.2 & $12 \%$ & $3 \%$ \\
\hline Capital $^{\dagger \dagger}$ & bil. yuan & 2425 & 1698 & $18 \%$ & $3 \%$ \\
\hline Labor & mil. persons & 22.8 & 15.2 & $2 \%$ & $1 \%$ \\
\hline Capital Compensation ${ }^{\dagger \dagger \dagger}$ & bil. yuan & 410 & 341 & $17 \%$ & $3 \%$ \\
\hline Labor Compensation ${ }^{\dagger \dagger \dagger}$ & bil. yuan & 341 & 263 & $15 \%$ & $2 \%$ \\
\hline
\end{tabular}

Notes: ${ }^{\dagger}$ The provincial mean is the mean over time of the variable in a province. Then the mean and S.D. reported here are the mean and standard deviation of those values ${ }^{\dagger}$ in constant 2000 yuan; ${ }^{\dagger \dagger}$ the sum of the two compensation items is equal to GDP; mil. and bil. indicate million and billion. 
Table 2. Fuel Cost Function Parameter Estimates

\begin{tabular}{c|cl|cl|ll}
\hline \multirow{2}{*}{ Parameter } & \multicolumn{2}{|c|}{ Between Estimator } & \multicolumn{2}{|c|}{ Difference Estimator } & \multicolumn{2}{c}{ Fixed Effects } \\
\cline { 2 - 7 } & Coefficient & $\begin{array}{l}\text { Standard } \\
\text { Error }\end{array}$ & Coefficient & $\begin{array}{l}\text { Standard } \\
\text { Error }\end{array}$ & Coefficient & $\begin{array}{l}\text { Standard } \\
\text { Error }\end{array}$ \\
\hline$\beta_{0}$ or $D\left(f_{t}\right)$ & -0.0090 & $0.0001^{* * *}$ & -0.0099 & $0.0001^{* * *}$ & & \\
$\beta_{C}$ & 0.2397 & $0.0004^{* * *}$ & 0.2272 & $0.0027 * * *$ & 0.2393 & $0.0018^{* * *}$ \\
$\beta_{G}$ & 0.1081 & $0.0029^{* * *}$ & 0.1038 & $0.0047 * * *$ & 0.1102 & $0.0045^{* * *}$ \\
$\beta_{X}$ & 0.4806 & $0.0005^{* * *}$ & 0.4877 & $0.0023^{* * *}$ & 0.4804 & $0.0013^{* * *}$ \\
$\beta_{D}$ & 0.1715 & $0.0029^{* * *}$ & 0.1813 & $0.0050^{* * *}$ & 0.1701 & $0.0048^{* * *}$ \\
$\beta_{C C}$ & 0.1810 & $0.0038^{* * *}$ & 0.1667 & $0.0143^{* * *}$ & 0.1819 & $0.0023^{* * *}$ \\
$\beta_{G C}$ & -0.0325 & 0.0199 & -0.0280 & 0.0297 & -0.0271 & $0.0074 * * *$ \\
$\beta_{G G}$ & -0.0236 & 0.1015 & -0.0763 & 0.0751 & 0.0930 & $0.0202^{* * *}$ \\
$\beta_{X C}$ & -0.1147 & $0.0029 * * *$ & -0.1007 & $0.0116^{* * *}$ & -0.1145 & $0.0042^{* * *}$ \\
$\beta_{X G}$ & -0.0430 & $0.0120^{* * *}$ & -0.0298 & $0.0088^{* * *}$ & -0.0501 & $0.0055^{* * *}$ \\
$\beta_{X X}$ & 0.2490 & $0.0020^{* * *}$ & 0.2369 & 0.0062 & 0.2480 & $0.0041^{* * *}$ \\
$\beta_{D C}$ & -0.0337 & $0.0190^{*}$ & -0.0380 & 0.0302 & -0.0403 & $0.0055^{* * *}$ \\
$\beta_{D G}$ & 0.0992 & 0.0988 & 0.1340 & $0.0705^{*}$ & -0.0158 & 0.0171 \\
$\beta_{D X}$ & -0.0912 & $0.0110^{*}$ & -0.1064 & $0.0127 * * *$ & -0.0834 & $0.0055^{* * *}$ \\
$\beta_{D D}$ & 0.0258 & 0.0983 & 0.0105 & 0.0740 & 0.1394 & $0.0154^{* * *}$ \\
$\gamma_{C}$ & 0.0031 & $0.0003^{* * *}$ & 0.0022 & $0.0006^{* * *}$ & 0.0037 & $0.0003^{* * *}$ \\
$\gamma_{G}$ & 0.0011 & 0.0029 & -0.0032 & $0.0014 * *$ & -0.0031 & $0.0013^{* *}$ \\
$\gamma_{X}$ & -0.0021 & $0.0003^{* * *}$ & 0.0005 & 0.0004 & -0.0016 & $0.0003^{* * *}$ \\
$\gamma_{D}$ & -0.0021 & 0.0029 & 0.0004 & 0.3806 & 0.0007 & 0.0012 \\
\hline
\end{tabular}

Note: $C, G, X$, and $D$ denote coal, gasoline, electricity, and diesel respectively. For BE first parameter is $\beta_{0}$, while for DE it is $D\left(f_{t}\right)$ - the average rate of cost reduction. Significance levels: * $10 \%$, ** 5\%, *** $1 \%$. 
Table 3: Fuel Total Own and Cross-Price Elasticities

\begin{tabular}{l|ll|ll|ll}
\hline \multirow{2}{*}{ Elasticity } & \multicolumn{2}{|c|}{ Between Estimator } & \multicolumn{2}{|c|}{ Difference Estimator } & \multicolumn{2}{c}{ Fixed Effects } \\
\cline { 2 - 7 } & Estimate & $\begin{array}{l}\text { Standard } \\
\text { Errors }\end{array}$ & Estimate & $\begin{array}{l}\text { Standard } \\
\text { Errors }\end{array}$ & Estimate & $\begin{array}{l}\text { Standard } \\
\text { Errors }\end{array}$ \\
\hline$\eta_{C C}^{T}$ & -0.085 & $0.015^{* * *}$ & -0.199 & $0.068^{* * *}$ & -0.030 & $0.010^{* * *}$ \\
$\eta_{C G}^{T}$ & -0.063 & 0.083 & -0.092 & 0.131 & -0.017 & 0.030 \\
$\eta_{C X}^{T}$ & -0.157 & $0.012^{* * *}$ & -0.298 & $0.053 * * *$ & -0.058 & $0.018^{* * *}$ \\
$\eta_{C D}^{T}$ & -0.026 & 0.079 & -0.113 & 0.136 & -0.019 & 0.022 \\
$\eta_{G C}^{T}$ & -0.061 & 0.184 & -0.202 & 0.291 & -0.037 & 0.065 \\
$\eta_{G G}^{T}$ & -1.111 & 0.938 & -1.704 & $0.727 * *$ & -0.059 & 0.195 \\
$\eta_{G X}^{T}$ & 0.083 & 0.115 & -0.141 & 0.088 & -0.035 & 0.057 \\
$\eta_{G D}^{T}$ & 1.089 & 0.907 & 1.345 & $0.699 *$ & 0.006 & 0.156 \\
$\eta_{X C}^{T}$ & 0.001 & 0.006 & -0.139 & $0.023 * * *$ & -0.029 & $0.009 * * *$ \\
$\eta_{X G}^{T}$ & 0.019 & 0.026 & -0.030 & 0.018 & -0.008 & 0.013 \\
$\eta_{X X}^{T}$ & -0.001 & 0.004 & -0.369 & $0.012^{* * *}$ & -0.063 & $0.008^{* * *}$ \\
$\eta_{X D}^{T}$ & -0.018 & 0.024 & -0.164 & $0.027 * * *$ & -0.025 & $0.012^{* *}$ \\
$\eta_{D C}^{T}$ & 0.043 & 0.111 & -0.142 & 0.168 & -0.027 & 0.031 \\
$\eta_{D G}^{T}$ & 0.686 & 0.579 & 0.770 & $0.383 * *$ & 0.004 & 0.101 \\
$\eta_{D X}^{T}$ & -0.051 & 0.068 & -0.442 & $0.072^{* * *}$ & -0.070 & $0.036 *$ \\
$\eta_{D D}^{T}$ & -0.678 & 0.573 & -0.888 & $0.408^{* *}$ & -0.032 & 0.082 \\
\hline
\end{tabular}

Note: $C, G, X$, and $D$ denote coal, gasoline, electricity and diesel respectively. First subscript is the quantity and second subscript is the price. Significance levels: * $10 \%$, ** 5\%, *** $1 \%$. 
Table 4: Interfuel Morishima and Shadow Elasticities of Interfuel Substitution

\begin{tabular}{|c|c|c|c|c|c|c|}
\hline \multirow[b]{2}{*}{ Elasticity } & \multicolumn{2}{|c|}{ Between Estimator } & \multicolumn{2}{|c|}{ Difference Estimator } & \multicolumn{2}{|c|}{ Fixed Effects } \\
\hline & Estimate & $\begin{array}{l}\text { Standard } \\
\text { Errors }\end{array}$ & Estimate & $\begin{array}{l}\text { Standard } \\
\text { Errors }\end{array}$ & Estimate & $\begin{array}{l}\text { Standard } \\
\text { Errors }\end{array}$ \\
\hline \multicolumn{7}{|l|}{ Morishima } \\
\hline$\mu_{C G}$ & -0.056 & 0.186 & -0.003 & 0.254 & -0.007 & 0.056 \\
\hline$\mu_{G C}$ & 1.083 & 0.965 & 1.612 & $0.765 * *$ & 0.042 & 0.200 \\
\hline$\mu_{C X}$ & 0.006 & 0.017 & 0.060 & 0.091 & 0.001 & 0.019 \\
\hline$\mu_{X C}$ & 0.003 & 0.012 & 0.071 & 0.062 & 0.005 & 0.023 \\
\hline$\mu_{C D}$ & 0.048 & 0.112 & 0.057 & 0.223 & 0.003 & 0.040 \\
\hline$\mu_{D C}$ & 0.709 & 0.573 & 0.775 & 0.489 & 0.012 & 0.096 \\
\hline$\mu_{G X}$ & 1.129 & 0.934 & 1.674 & $0.733 * *$ & 0.051 & 0.206 \\
\hline$\mu_{X G}$ & 0.084 & 0.118 & 0.228 & $0.089 * *$ & 0.029 & 0.061 \\
\hline$\mu_{G D}$ & 1.797 & 1.511 & 2.474 & $1.093 * *$ & 0.063 & 0.289 \\
\hline$\mu_{D G}$ & 1.767 & 1.476 & 2.233 & $1.096 * *$ & 0.037 & 0.236 \\
\hline$\mu_{X D}$ & -0.05 & 0.064 & -0.073 & 0.072 & -0.007 & 0.037 \\
\hline$\mu_{D X}$ & 0.66 & 0.576 & 0.724 & $0.393 *$ & 0.007 & 0.070 \\
\hline \multicolumn{7}{|l|}{ Shadow } \\
\hline$\sigma_{C G}$ & 0.729 & 0.687 & 1.105 & $0.563 * *$ & 0.027 & 0.142 \\
\hline$\sigma_{C X}$ & 0.005 & 0.015 & 0.063 & 0.081 & 0.003 & 0.020 \\
\hline$\sigma_{C D}$ & 0.433 & 0.339 & 0.456 & 0.350 & 0.009 & 0.069 \\
\hline$\sigma_{G X}$ & 0.938 & 0.760 & 1.420 & $0.610 * *$ & 0.047 & 0.176 \\
\hline$\sigma_{G D}$ & 1.786 & 1.492 & 2.386 & $1.075 * *$ & 0.053 & 0.264 \\
\hline$\sigma_{X D}$ & 0.473 & 0.428 & 0.508 & $0.275^{*}$ & 0.003 & 0.042 \\
\hline
\end{tabular}

Note: $C, G, X$, and $D$ denote coal, gasoline, electricity and diesel respectively. For cross-price elasticities, the first subscript is the quantity and second subscript is the price. For Morishima elasticities the first subscript is the price that changes. Significance levels: * $10 \%, * * 5 \%, * * * 1 \%$. 
Table 5: Factor Cost Function Parameter Estimates

\begin{tabular}{|c|c|c|c|c|c|c|}
\hline \multirow[b]{2}{*}{ Parameter } & \multicolumn{2}{|c|}{ Between Estimator } & \multicolumn{2}{|c|}{ Difference Estimator } & \multicolumn{2}{|c|}{ Fixed Effects } \\
\hline & Coefficient & $\begin{array}{l}\text { Standard } \\
\text { Error }\end{array}$ & Coefficient & $\begin{array}{l}\text { Standard } \\
\text { Error }\end{array}$ & Coefficient & $\begin{array}{l}\text { Standard } \\
\text { Error }\end{array}$ \\
\hline$\beta_{0}$ & -0.5661 & $0.0053 * * *$ & & & & \\
\hline$\beta_{E}$ & 0.1268 & $0.0054 * * *$ & 0.2179 & $0.0750 * * *$ & 0.1471 & $0.0235 * * *$ \\
\hline$\beta_{K}$ & 0.4763 & $0.0053 * * *$ & 0.4171 & $0.0401 * * *$ & 0.3833 & $0.0147 * * *$ \\
\hline$\beta_{L}$ & 0.3968 & $0.0039 * * *$ & 0.3650 & $0.0363 * * *$ & 0.4697 & $0.0165 * * *$ \\
\hline$\beta_{E E}$ & 0.0687 & $0.0340 * *$ & 0.0174 & 0.0494 & 0.1071 & $0.0094 * * *$ \\
\hline$\beta_{K E}$ & -0.0863 & $0.0295 * * *$ & -0.0388 & $0.0218 *$ & -0.0691 & $0.0056^{* *}$ \\
\hline$\beta_{K K}$ & 0.0569 & $0.0309 *$ & 0.1140 & $0.0298 * * *$ & 0.1657 & $0.0074 * * *$ \\
\hline$\beta_{L E}$ & 0.0175 & 0.0126 & 0.0214 & 0.0358 & -0.0379 & $0.0068 * * *$ \\
\hline$\beta_{L K}$ & 0.0294 & $0.0133 * *$ & -0.0752 & $0.0285^{* * *}$ & -0.0965 & $0.0071 * * *$ \\
\hline$\beta_{L L}$ & -0.0469 & $0.0101 * * *$ & 0.0538 & 0.0367 & 0.1344 & $0.0090 * * *$ \\
\hline$\gamma_{E}$ & 0.0144 & 0.0093 & -0.0012 & 0.0022 & 0.0153 & $0.0029 * * *$ \\
\hline$\gamma_{K}$ & -0.0039 & 0.0058 & 0.0138 & $0.0034 * * *$ & -0.0008 & 0.0028 \\
\hline$\gamma_{L}$ & -0.0105 & 0.0066 & -0.0126 & $0.0035^{* * *}$ & -0.0145 & $0.0015 * * *$ \\
\hline
\end{tabular}


Table 6: Factor Own and Cross-Price Elasticities, Morishima, and Shadow Elasticities of Substitution

\begin{tabular}{|c|c|c|c|c|c|c|}
\hline \multirow[b]{2}{*}{ Elasticity } & \multicolumn{2}{|c|}{ Between Estimator } & \multicolumn{2}{|c|}{ Difference Estimator } & \multicolumn{2}{|c|}{ Fixed Effects } \\
\hline & Estimate & $\begin{array}{c}\text { Standard } \\
\text { Errors }\end{array}$ & Estimate & $\begin{array}{c}\text { Standard } \\
\text { Errors }\end{array}$ & Estimate & $\begin{array}{c}\text { Standard } \\
\text { Errors }\end{array}$ \\
\hline \multicolumn{7}{|l|}{$\begin{array}{l}\text { Own \& } \\
\text { Cross-price }\end{array}$} \\
\hline$\eta_{E E}$ & -0.331 & 0.266 & -0.702 & $0.235 * * *$ & -0.125 & 0.126 \\
\hline$\eta_{E K}$ & -0.204 & 0.232 & 0.239 & $0.100 * *$ & -0.087 & 0.081 \\
\hline$\eta_{E L}$ & 0.535 & $0.102 * * *$ & 0.463 & $0.180 * * *$ & 0.212 & $0.058 * * *$ \\
\hline$\eta_{K E}$ & -0.054 & 0.062 & 0.125 & 0.079 & -0.033 & 0.026 \\
\hline$\eta_{K K}$ & -0.404 & $0.065 * * *$ & -0.310 & $0.070 * * *$ & -0.184 & $0.019 * * *$ \\
\hline$\eta_{K L}$ & 0.629 & $0.105 * * *$ & 0.020 & 0.147 & -0.187 & $0.099 *$ \\
\hline$\eta_{L E}$ & 0.171 & $0.031 * * *$ & 0.277 & $0.126^{* *}$ & 0.066 & $0.028 * *$ \\
\hline$\eta_{L K}$ & 0.550 & $0.032 * * *$ & 0.211 & $0.104 * *$ & 0.178 & $0.024 * * *$ \\
\hline$\eta_{L L}$ & -0.721 & $0.023 * * *$ & -0.488 & $0.100 * * *$ & -0.244 & $0.020 * * *$ \\
\hline \multicolumn{7}{|l|}{ Morishima } \\
\hline$\mu_{E K}$ & 0.277 & 0.324 & 0.827 & $0.268 * * *$ & 0.092 & 0.150 \\
\hline$\mu_{K E}$ & 0.200 & 0.292 & 0.548 & $0.144 * * *$ & 0.098 & 0.086 \\
\hline$\mu_{E L}$ & 0.502 & $0.282 *$ & 0.979 & $0.319 * * *$ & 0.191 & 0.152 \\
\hline$\mu_{L E}$ & 1.256 & $0.112 * * *$ & 0.951 & $0.252 * * *$ & 0.456 & $0.073 * * *$ \\
\hline$\mu_{K L}$ & 0.955 & $0.082 * * *$ & 0.521 & $0.153 * * *$ & 0.362 & $0.037 * * *$ \\
\hline$\mu_{L K}$ & 1.350 & $0.118 * * *$ & 0.508 & $0.209 * *$ & 0.057 & 0.111 \\
\hline \multicolumn{7}{|l|}{ Shadow } \\
\hline$\sigma_{E K}$ & 0.261 & 0.313 & 0.731 & $0.214 * * *$ & 0.093 & 0.131 \\
\hline$\sigma_{E L}$ & 0.685 & $0.229 * * *$ & 0.969 & $0.285 * * *$ & 0.254 & $0.138^{*}$ \\
\hline$\sigma_{K L}$ & 1.170 & $0.093 * * *$ & 0.514 & $0.163 * * *$ & 0.225 & $0.054 * * *$ \\
\hline
\end{tabular}

Note: $E, K$ and $L$ denote capital, energy and labor respectively. For Morishima elasticities the first subscript is the price that changes. Significance levels: * 10\%, ** 5\%,***1\%.Significance levels: * 10\%, ** 5\%, *** $1 \%$. 


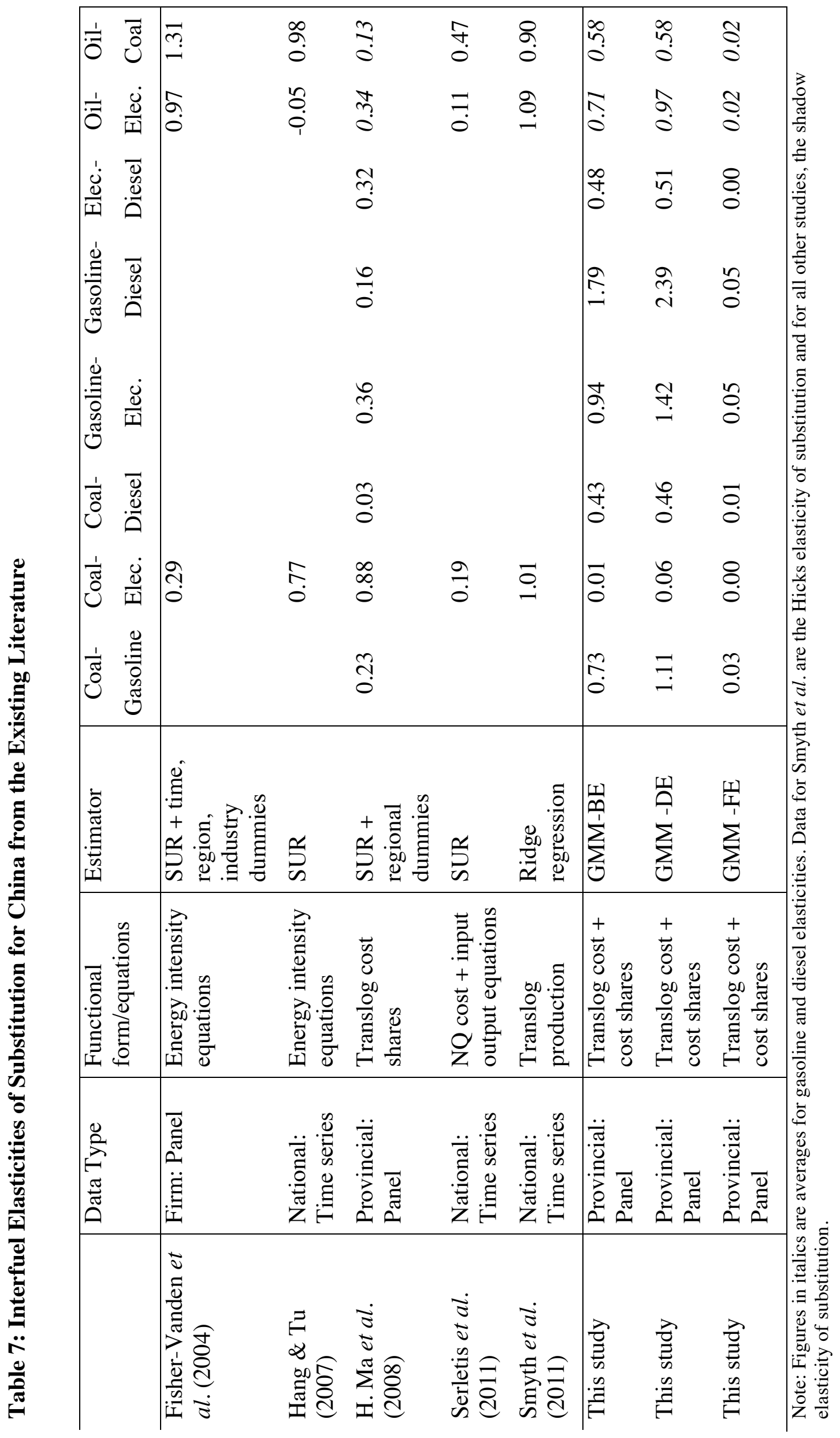




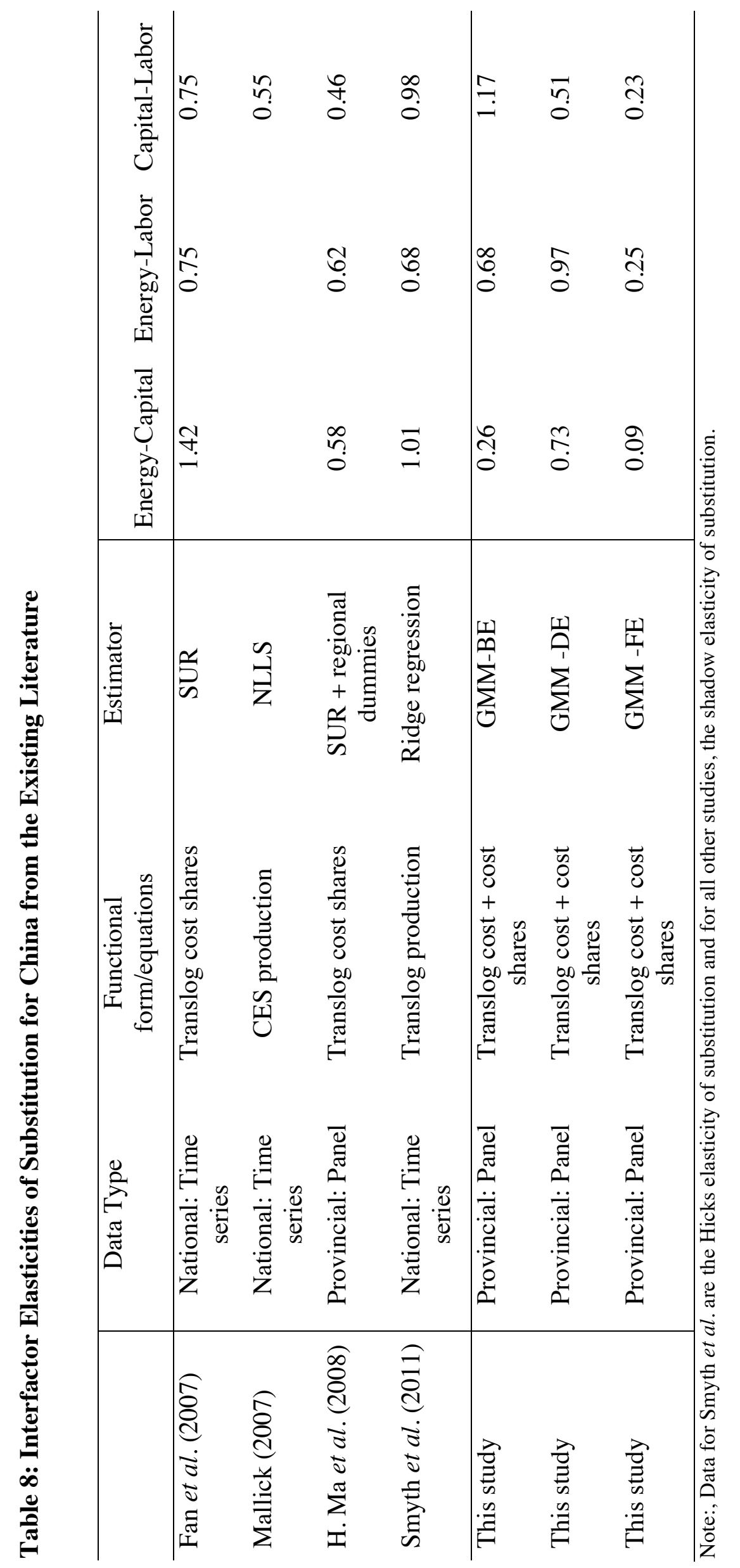


Figure 1. Laspeyres Coal Price Index 2010

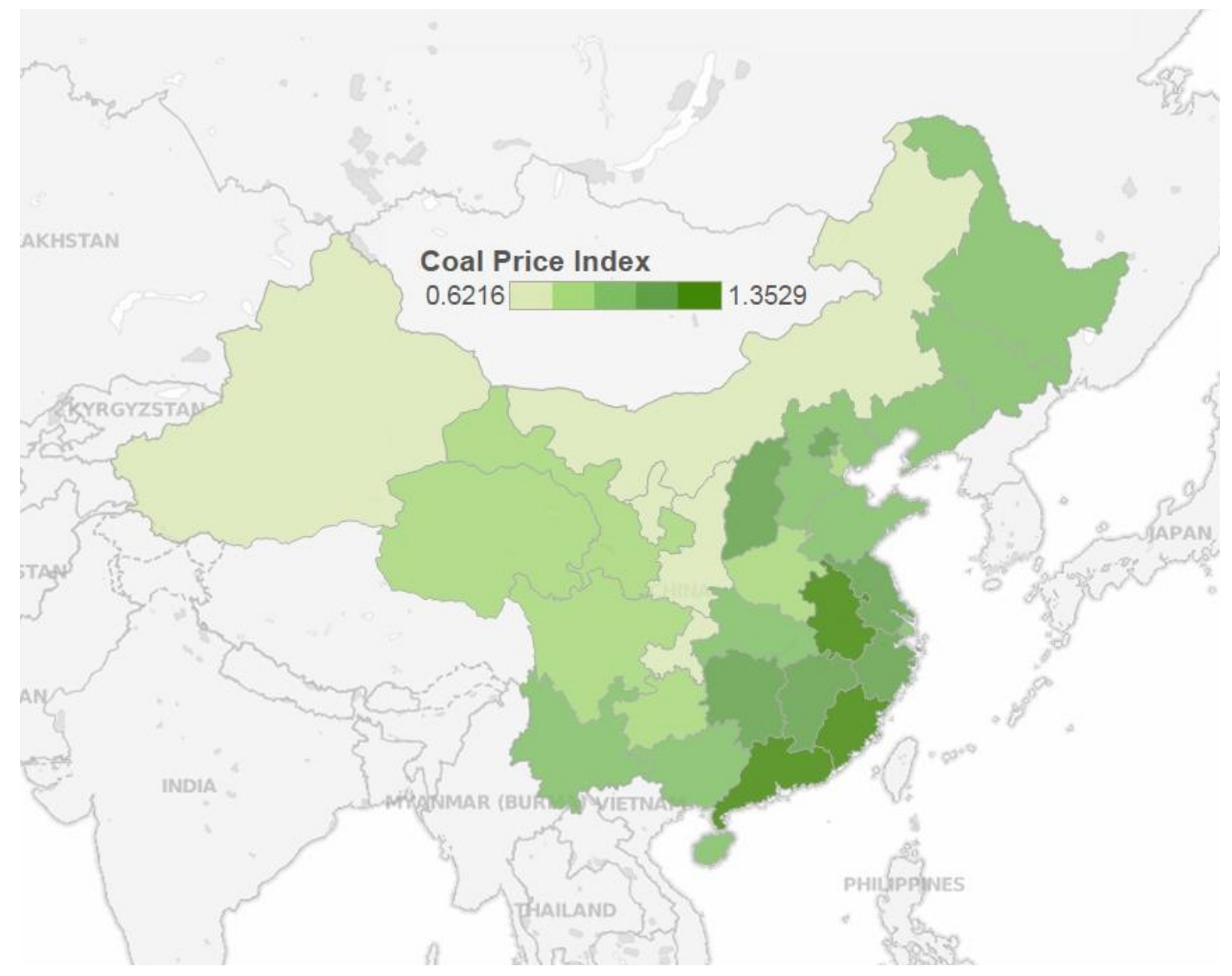


Figure 2. Log Distance from the Frontier 2010

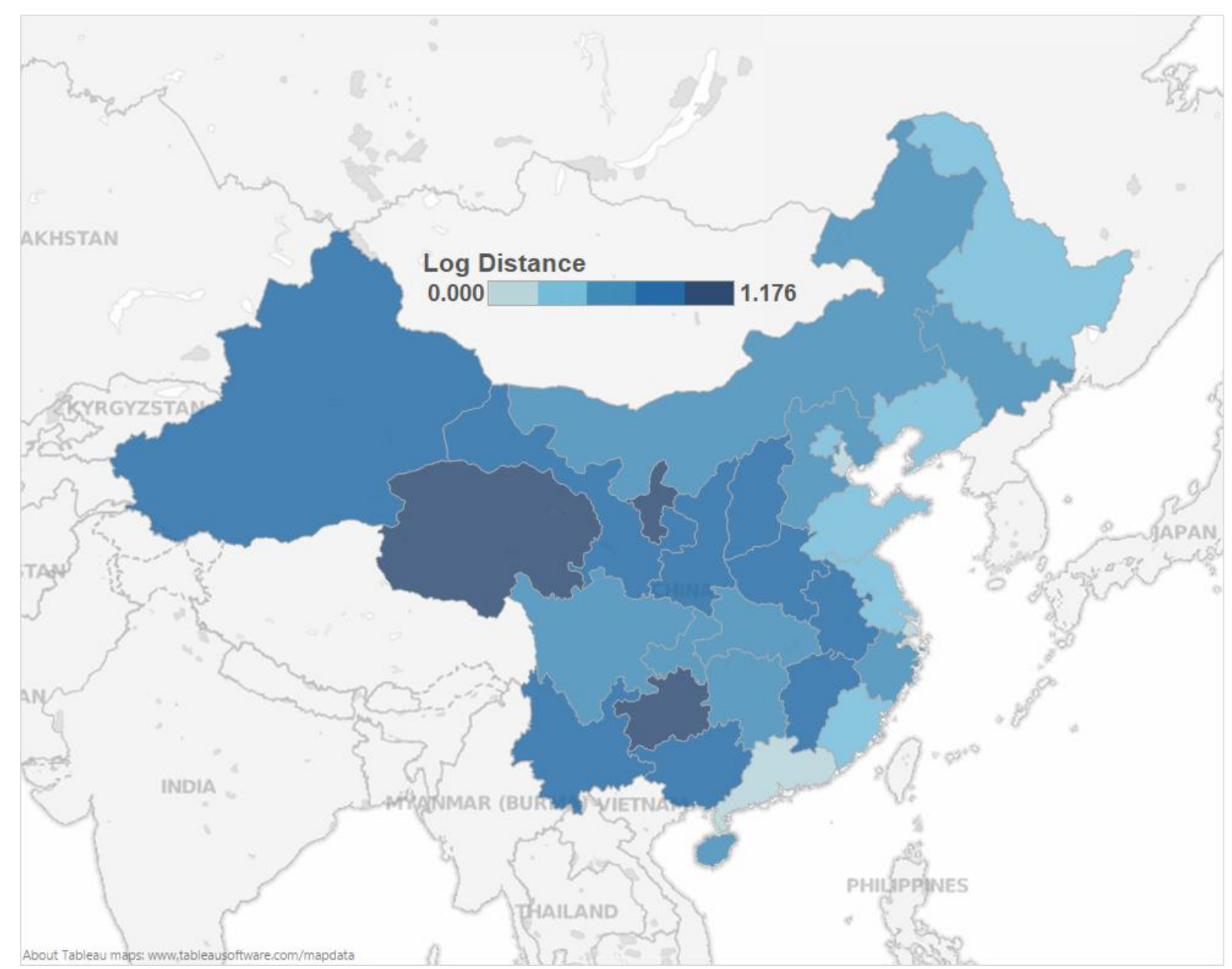


Figure 3. Growth Rate of TFP 2000-2010

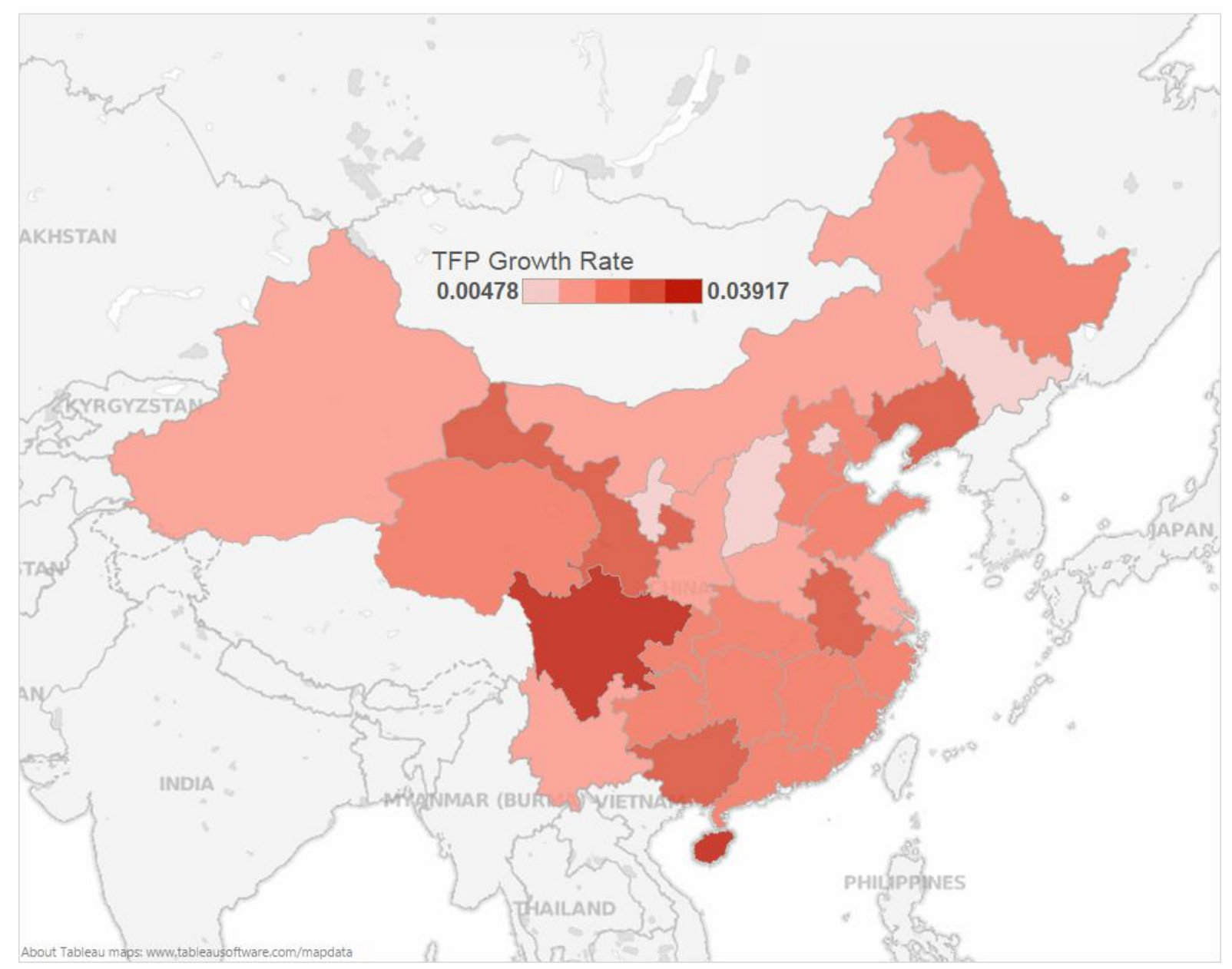

